THE EARLY STAGES OF AN EXPERIMENTAL PIAARACHNOIDITIS IN THE RABBIT (WITH ILLUSTRATIONS).

By JOHN GERALD FITZGERALD,

Clinical Director Toronto (Ontario) Asylum,

(From the Laboratory of the Sheppard and Enoch Pratt Hospital, Toweson, Baltimore, $M d$.)

This piece of work was undertaken with a view of studying the tissue changes in the pia-arachnoid from day to day, occurring as the result of a sterile inflammation caused by chemical irritation in the form of glacial acetic acid. It is hoped that this work may add something to the present knowledge of the condition of the pia-arachnoid, in an acute inflammatory state: it is hardly necessary to add that many very inviting by-paths present themselves and offer valuable fields for study and investigation, but owing to the limited time at my disposal it was imperative that the work should not assume other than the most modest proportions. However, even with this in mind it has been found impossible to entirely dissociate the changes occurring in the piaarachnoid, under the conditions to be described, from those occurring in the underlying superficial layers of the cortex cerebri.

The technique will be first described in order that a clear understanding of the etiologic factors of the inflammation may be gained.

The animals used in the experiments were young adult rabbits, of a uniform age as far as possible. This uniformity of age, of course, was of the utmost importance, because in young rabbits the changes in the elements of the normal pia are conspicuous from week to week. So if we were to learn anything of the changes occurring, almost like the changing views of a panorama, the careful observance of this rule was absolutely necessary. Despite the fact that the rabbits were of the same age approximately, and that any variation was noted, it was found necessary to take 
a piece of normal tissue from each animal and use it as a control in the study of the inflamed area.

Eleven rabbits in all were used, one was a nurmal rabbit on which no operation was done. The others were all operated upon and represented the various stages in the inflammatory process from one day up to ten. The technique employed in the operations was as follows: The rabbits were prepared for operation in the usual way-the hair on the top of the head being carefully shaved, the vertex being then scrubbed successively with potassium permanganate, oxalic acid and bichloride. An incision was then made in the middle line extending from the frontal to the occipital region. The periosteum being thus exposed was carefully scraped back over the areas which were to be trephined.

The trephine opening was made on each side of the middle line, one somewhat anterior and the other posterior, because it was found that when the openings were directly opposite, there was much more liability of disturbing the button which had just been replaced, than when the opening was not so exposed. The small trephine openings were now made, the buttons being carefully placed to one side. A known quantity of glacial acetic acid was then applied. A small pipette of fine bore was used for this purpose, which was so graduated that the amount of fluid used could be estimated. On one side a small amount of acid was applied (usually $2 \mathrm{~cm}$.), and this was known as the weak irritant which of course caused the mild lesion. On the other side the strong irritant was applied (usually $5 \mathrm{~cm}$.) and the resulting lesion was the severe one. It must of course be kept in mind that the words "weak" and "strong" are here given relative quantitative values, the quality being the same in each instance.

Directly the acid was applied the buttons were replaced and the periosteum scraped back over the openings, and finally the scalp was sewed up. A collodion dressing was applied and the rabbit liberated.

In order that our results might be as accurate as possible, notes on the condition of the animal while on the table and after being liberated were made. Also on their condition in the time intervening between the operation and the time when they were etherized. Nearly all the animals were running about eating 
grass in less than twelve hours after operation, apparently as well as ever, any exceptions to this are noted hereafter.

It goes without saying that the operations were all done under strictly aseptic conditions, because the presence of an infection would greatly interfere with the results obtained by causing an increased number of leucocytes to be present in the early stages and causing destruction of areas of tissue rendering them unfit for careful study. Certain other points in connection with the treatment of the tissue after the death of the rabbit until the tissue was ready for study are worth noting. First, it was found most convenient to kill the rabbits by etherizing. This could be done quickly and the tissue could be quickly removed before the post-mortem changes had set in. As soon as the bone was removed and the brain exposed, it was kept moist by normal saline, this prevented the membranes from drying out and kept the tissue in a normal state until it could be fixed. Three per cent nitric acid was first applied to the tissue in situ-as fixative, small blocks were then removed and put through 50 per cent, 60 per cent, 70 per cent, 80 per cent, 90 per cent, 96 per cent alcohol successively, the 96 per cent being changed three times in the first 24 hours. After this the tissue was dealt with in the usual way, celloidin being used for embedding.

The constituents of the pia-arachnoid with which we had to deal were simply mesodermal elements, all being derived from the same source (that is the simple mesoblastic connective-tissue cell) by a process of differentiation. We had also to deal with fixed connective-tissue cells-those going to make up the walls of the blood-vessels, the adventitial cells, muscle cells and endothelial cells-all these were seen in various forms, young, adult, and also certain transition forms. We had finally to consider the different hæmatogenous elements which made their appearance at times.

The normal pia-arachnoid is made up of long connective-tissue cells joined end to end being frequently bulging in the center and pointed toward either end, the nuclei containing many small chromatin granules. Other nuclei are more or less irregularly oval in outline also containing masses of chromatin. A distinct membrana limitans externa and interna can at times be made out. These membranes are simply chains of flattened endothelial cells 
lying end to end. Lying between these rows of cells are the connective-tissue strands. The blood-vessels are everywhere quite numerous in the pia-arachnoid, being separated from one another by varying intervals. Some of the vessels run parallel with the membranes and others run at right angles. They vary considerably in size, from quite small ones to vessels of fairly good size-in many places branches of the vessels can be traced for a short distance into the cortex cerebri. In some instances the limiting membranes of the pia-arachnoid served also as the adventitial layer of the blood-vessel wall. In the normal pia there are no hæmatogenous elements free in the tissue, and it is only after some inflammatory process has been set up that these are found. The connection between the glia fibers and connective-tissue strands in the pia-arachnoid was also seen, long processes of the glia cells running down to the pia. The presence of a small amount of elastic tissue and of collaginous fibers in the pia should be kept in mind.

The rabbit selected for experiment No. I was a healthy young adult. The operative procedure before described was carried out, the animal stood the operation well and appeared quite lively after being released from the operating table. Until the time when it was killed 24 hours later, nothing unusual was noted. Immediately after death a section was made and the tissue secured. After being put through in the manner described elsewhere, sections were cut which were stained with Thionin and by the Van Gieson method.

The thionin sections were first studied as they show the changes which one would naturally expect to find at such an early stage of the inflammatory process. It was at once apparent even with the low power that the changes in the pia-arachnoid at this time were largely due to the presence of foreign elements-in other words to the presence of a hæmatogenous exudate. The thickness of the pia was apparently increased, and this was very well seen in sections in which could be compared in the same field of the microscope normal pia and pia that showed changes due to the presence of a pathologic process. With the high power the pia appeared to be swollen and the presence of the exudate was more clearly seen. On could also make out now three zones. The first or central zone showing the injured pia overshadowed 
by the hæmatogenous exudate, this being the area where the regressive changes were seen in their most characteristic form. Just outside this and somewhat less in extent transversely was the zone where the pia elements could be seen to have increased in number; where progressive changes were going on, and finally zone number three; that which was most peripherally situated, being almost normal pia.

It is interesting to study the appearances in each of these zones separately. In the central zone, there were scattered everywhere throughout, irregular masses of chromatin, in almost every conceivable shape and form. Some which had undergone the least changes, were irregularly horse-shoe in shape and were at once recognized as nuclei of polymorphonuclear leucocytes, of which the cytoplasm had entirely disappeared. In many other instances the chromatin was arranged much more irregularly, sometimes as rows of small round granules, in other places as curiously shaped figures composed of a number of small granules. These masses of chromatin were scattered everywhere throughout this area, and they were the most conspicuous element present. Owing to their large number they obscured the pia elements and the normal network appearance was quite obliterated. Lying just inside the endothelial layer of the blood-vessels lymphocytes were seen, and the other elements which after the polynuclear chromatin masses, were perhaps the most characteristic of this stage-that is the plasma cells. They were seen in all stages, from the young cells still presenting features of the lymphocytes (from which they are probably derived) namely, the lightly staining cytoplasm with nucleus containing distinct chromatin clumps, to the full-grown cell with eccentric, blue lightly stained nucleus, and the purple cytoplasm containing many granules and in some showing the characteristic appearance of the plasma cell where the protoplasm toward the center being somewhat rarefied and staining less intensely appeared almost like a vacuole. The nuclei of these cells were in many instances quite irregular in outline, and the cells themselves showed no definite cell membrane. The plasma cells so far having showed no proliferative changes, (i. e., mitosis) after reaching adult form they commenced to show regressive changes.

It will thus be seen that where the irritant was most active, at 
the height of the curve, so to speak, the changes were chiefly regressive. But passing over to where the action of the chemical was less severely felt, it is apparent that we have to do with a progressive process. The pia elements have been stimulated, they were increased in number, as was evidenced by the increased width of the pia, and this could be seen to be due, not to the presence of the hæmatogenous elements as in the former case, but to a proliferation of the connective-tissue elements of the pia. Where it was possible to trace a small capillary through the pia into the cortex, the vessel wall showed certain changes indicating activity in the mesodermal elements in the immediate neighborhood; in the walls of the vessels just beyond the nuclei little reticulated areas could be made out. In parts of the cortex where the stimulating effect of the irritant had not been felt by the vascular elements only the nuclei could be made out.

The vessels themselves appeared swollen, the lumina appeared wider than normal. In all cases the lumen contained large quantities of red cells and and a considerable number of polynuclears. An occasional vein could be distinctly made out in the pia-arachnoid, and here also the lumen could be more easily made out than in the normal pia where no inflammatory change was present. The endothelial cells in the wall with their nuclei could be differentiated.

In many instances the condition of the vessel wall suggested the beginning of an active proliferative process-this was most conspicuous just out side the acute zone where the changes were all more or less regressive. The presence also of fibroblasts suggested an active proliferating process in the pia, and for this reason beginning mitotic changes were carefully looked for, and although there were ceratin appearances which strongly suggested mitosis, no definite picture of cell division was seen at this period.

With the Van Gieson stain an increase in the amount of collagenous material could be made out. This being practically the only observation that could be made from an examination of the Van Gieson pictures; other than those noted in sections stained by thionin.

So it was clear that the picture that presents itself at the end of the first $\mathbf{2 4}$ hours in an acute inflammatory condition artificially induced under aseptic conditions is chiefly of a hæmatogenous na- 
ture. The changes being both accumulative and regressive, the latter being most in evidence as was seen by the great masses of polynuclear leucocytes undergoing degenerative changes. At the same time the stimulation of the tissues just outside the actually wounded area had clearly brought about the reparative process, this being evidenced by the activity in the elements of the vessel walls.

In the case of the rabbit used in this experiment, owing to the amount of irritant used having been small, no marked changes in the cortex cerebri were anticipated and this proved to be the case. There was slight damage to some of the ganglion cells due to the direct action of the irritant and the mesodermal elements which run into the cortex from the pia-arachnoid, showed the changes here as elsewhere. But, the mesodermal elements are really foreign to the cortex cerebri, not being related to the specific constituents of the gray matter in origin, development or function, simply supplying the layers of the cortex with its blood supply and having other functions entirely dissimilar to those of the native tissue.

Next were studied the changes at the end of the second 24 hours-that is, the conditions found at the end of 48 hours. It was noted at the time of operation that the rabbit used for the experiment was not quite fully grown. It stood the operation well and no untoward incident was noted up to the time of death.

With the low power the area of the lesion could be seen and definitely limited and the normal pia-arachnoid on either side followed. With this magnification it was evident also that the exudative condition with which we had to deal in the 24-hour sections had largely subsided, and because the pia was definitely increased in amount at the site of the lesion, the only solution was that active progressive changes had superseded the regressive ones which were so conspicuous before at the site of the lesion. With the $1 / 12$ power the first striking fact was the disappearance in large part of the chromatin masses that were present in such large quantities 24 hours previously. The masses were comparatively rare and scattered at irregular intervals. The fact that these masses of chromatin had largely disappeared; and the other hæmatogenous element, which largely dominated the 24-hour picture, namely, the plasma cell, was not seen in its typical form; 
naturally suggested the probability that certain elements had arrived whose function was phagocytic. This proved to be the case and we saw for the first time cells which in common with certain other workers I shall hereafter speak of as " reticulated cells." Before going further, it would perhaps be well to digress to the extent of clearly explaining the nature of the cell of which I wish to speak at some length.

They have been called "fatty granular cells" and "Epitheloid" cells, also "Gitterzellen," lattice cells, so described by Juliusburger and Boedecker and this name Nissl also applies to them. They are found chiefly in lesions of the brain where there has been actual destruction of tissue and it has been recognized for some time that their function is largely phagocytic, and this point Nissl has emphasized. This fact was clearly recognizable in our sections, as several of the cells contained foreign bodies. Their appearance in the adult form is as follows: They vary considerably in size, they are as a rule irregular in outline; they have no definite cell membrane, they are made up of numerous vacuoles joining together, the cytoplasm being confined to the thin threadlike trabeculæ which bind the vacuoles. The cell itself stains lightly. The nucleus is, in the characteristic cell, peripherally situated. It stains quite deeply and is in marked contrast to the cell body. There is no definite nucleolus, but the nucleus contains irregular masses of chromatin which stain very deeply as a rule, also there are other small granules of chromatin scattered throughout the nucleus.

In the sections which we are at present dealing with these cells were confined to the arachnoid spaces. None were seen in the cortex. The vacuolations could be made out more clearly in some than in others. In certain cells there were only two or three conspicuous vacuoles, the others being much less marked. The vacuoles which were as a rule most noticeable contained foreign bodies (some resembled chromatin masses, others appeared like red-blood cells), and this appearance is characteristic. The cells were not very numerous at this stage. They showed no evidence of mitosis and their appearance was probably synchronous with the next element which we have to describe, namely, the fibroblast in an active proliferating state.

This element is a product of the simple embryonic mesodermal 
cells from which the more highly differentiated adventitial and endothelial cells are developed. Their appearance in the lesion at this stage was characteristic, the slightly elongated, irregularly oval nucleus; staining rather lightly as did also the cell protoplasm, the mesh-like appearance just outside the nucleus where a number of small very irregular meshes could be made out. This condition is always found in the active fibroblast. The nucleus contains scattered irregular clumps of chromatin.

All through the section fibroblast nuclei were much in evidence and a great many tended to assume a spherical form. The most striking feature about the fibroblasts was their activity. Everywhere the process of mitosis could be seen. Cells were seen in all stages of division, and in many instances, one could see in the same field chromatin clumps assuming a polar arrangement and the adjacent cell just divided. Many of these cells undergoing mitosis were seen in almost every field, particularly over the site of the lesion, and they were one of the most characteristic appearances in the 48-hour picture.

The newly formed fibroblasts tended to run in parallel lines (fibroblast trains) and to form the wall of new blood-vessels.

Mitosis was also seen occurring in the endothelial cells in the walls of the veins, and was characterized by the bulging out of the wall of the nucleus and the usual arrangement of the chromatin. Similar mitoses were seen in the walls of the capillaries in the cortex.

These were the features in the pia at the end of 48 hours which were the most conspicuous, and it is evident that the changes going on at this time were largely progressive in character. Wherever in the tissue there had been very evident destruction, the connective tissue as we have seen, was undergoing active proliferative changes which had been stimulated by the inflammatory process.

Certain changes in the layers of the cortex directly under the lesion will be noticed just for a moment. Many of the ganglion cells were seen to have been severely injured by the irritant action of the acid. They showed very considerable nuclear changes with breaking down in the cell body. In one instance where the cell protoplasm stained only faintly and where the cell outline was not at all clear, in the nucleus the nucleolus was deeply 
stained and was peripherally situated. This condition of degeneration in the ganglion cell was not seen elsewhere than in the zone of the lesion. Certain accompanying glia changes were also observed. Many of the glia nuclei were larger than normal, the chromatin granules were larger and stained more deeply, and the protoplasmic processes of the glia cell bodies could be more easily followed. Clusters of glia nuclei were also seen, three or four glia nuclei were seen in one cell overlapping one another, but the outline of each one could be distinctly seen. The cell itself appeared irregular in outline, the protoplasm had partially disappeared, but scattered throughout small peripheral basophilic particles could be seen. As the work is to deal chiefly with changes in the pia, further observations on the existing conditions in the cortex cerebri are not recorded.

Before proceeding to a consideration of the changes observed at the end of 72 hours, I would say that many forms of the reticulated cells were observed which were chiefly characterized by the presence of one large vacuole clearly to be seen, and a number of others much more difficult to distinguish as such. The sections studied to show the changes present at the end of 48 hours were Thionin preparations. A study of the Van Gieson sections showed very well the increased amount of the connective tissue present, and this could be well demonstrated with the low power where one was able to bring into one field, the area which had been treated with the irritant and areas of normal pia on either side. When this was done, the increased thickness of the pia over the site of the lesion was seen to be due to the proliferation of connective tissue-the various forms of adventitial and endothelial nuclei were also well seen here; and their appearance was compared with that of the fibroblast nuclei; these latter being nearly always spherical, the type of the embryonic mesodermal tissue cell nucleus; the adventitial and endothelial, were nearly always seen to be flattened, elongated structures. In many instances it was difficult to make out their cell protoplasm. The mitotic activity of the endothelial and adventitial nuclei was much less marked than in the case of the fibroblasts; and this of course was to be expected, as the fixed tissue elements take a less active part in the proliferative processes than do the fibroblasts and are less in evidence where the process of repair is going on. Of 
course as the fibroblasts develop, many of them, as was noted before, serve in the formation of the walls of the new vascular channels.

The animal used in the third experiment was a young fullgrown rabbit. It was etherized 72 hours after the operation. Nothing of interest occurred between the time when the animal was operated upon until it was killed. A study of the sections at this stage showed many interesting developments. It was at once apparent even with the No. 6 power that we had largely to do with fibroblastic activity, and it could also be demonstrated that the changes were to be found chiefly in the molecular zone in the cortex. The sections did not present the picture of a greatly thickened pia as sections made earlier had done. Instead, the striking feature was the connective-tissue invasion of the molecular zone. Everywhere strands of connective tissue either in the form of new vascular channels or as fibroblast trains could be seen.

With the $I / 12$ power were noted the increase in the connectivetissue elements, the invasion of the molecular zone and the marked absence of the hæmatogenous elements which was so conspicuous at the end of 24 hours and could still be seen at the end of the second day. It will perhaps be better to discuss the changes in the various elements in a categorical fashion-and we will begin with the connective-tissue elements, present in most striking numbers as fibroblasts.

These cells presented the same appearance that was noted in the previous sections-the rather elongated nucleus rounded at either end containing a rich chromatin strand which stained deeply, the rest of the protoplasm in the nucleus staining much less intensely, and the cytoplasm often being still more difficult to distinguish because of the small amount of stain which it had taken up. They were in an extremely active condition; all stages of mitosis being seen. They varied considerably in size according to their age. Some of the cells which had made their appearance some time before being of quite large size. The newly formed fibroblasts in many instances soon joined to form new blood-vessels, and when they assumed the condition of a fixed tissue cell their appearance changed somewhat, this being due, of course, to a decrease in their functional activity-then they were 
much less likely to undergo mitosis-the chromatin of the nucleus was decreased in amount and the staining of the cell body and the nucleus was more uniform.

The activity of the fibroblasts was not solely confined to those found in the molecular zone. Occasionally a mitosis would be seen in a fibroblast deep down in the layers of the cortex. Everywhere the appearance was characteristic of activity of the mesodermal elements.

The hæmatogenous exudate had practically disappeared. No plasma cells were seen. Some chromatin masses, the remains of broken down polynuclears were occasionally seen, but they were quite few in number. The regressive changes in the leucocytes had gone on to such an extent that it was often extremely diffcult to recognize various forms which were seen. These were scattered about in the cortex and could only be differentiated from certain regressive forms of glia nuclei by a careful search for other forms in earlier or later stages whose character we knew.

The increase in the number of reticulated cells was quite striking-with the fibroblasts they were as a rule the chief constituents of any field. The adult forms were first studied and quite a number was seen, whose nuclei were extremely irregular in outline, where the vacuoles were small and where there was an appearance of cell membrane, but this, of course, was not present. However, by far the greatest number of those seen were perfectly characteristic forms, large and containing on the average from about 15 to 17 vacuoles, the nucleus was eccentric, and there was no suggestion of a cell membrane while the cells were, as a rule, quite regular in outline, as was also the nucleus. Some of the irreguar forms of the reticulated cells contained dumb-bell shaped nuclei which strongly suggested a beginning mitosis, but this was never actually seen. Some of the reticulated cells had a tailpiece of protoplasm - the tag end of the cytoplasm which had not yet been taken up into the cell body. These were not altogether unlike the pseudopodia which the reticulated cell does throw out when surrounding a foreign body; but at the same time it was quite evident that the little tags were not pseudopodia, but in all probability the tag of protoplasm showing where division had taken place. The fact that the reticulated cells were found every- 
where in the cortex, emphasized the fact that they are the wandering cells most usually seen there.

It happened that in the sections which were studied at this time the function of the reticulated cells, namely, phagocytosis was not seen as well as in certain fields in the 48-hour sections, and the possible explanation of this is that the cells at this particular period were more actively engaged in division than at other periods. And it could be seen that they were more actively engaged in mitosis than at any other stage. Everywhere the characteristic change in the cytoplasm and nucleus preparatory to division were seen and the various stages could be studied. The cytoplasm showed a deeper staining reaction, the vacuoles were much less conspicuous, in fact in some cells they had quite disappeared - the cell body became more compact, the chromatin masses in the nucleus assumed the form of a rosary-a single row of small clumps arranged in a circular fashion about the nuclear membrane. Later the two polar bodies could be seen, the filaments running from one to the other could also be made out and along their course little basophilic granules were seen. These granules were chiefly confined to the rows of filaments, but a few had strayed out to the edge of the nucleus just outside the nuclear membrane.

A curious feature was noted in connection with the reticulated cells, and it was that many cells in the process of mitosis were lying close to capillaries, and it is possible that reticulated cells so situated show more active proliferation. Of course, many of these cells were also seen dividing at a considerable distance from any vascular channel.

As one would expect, since the site of the changes seen at this period was the molecular zone, the changes in the cortex were more conspicuous than at any other period so far investigated. The most striking feature was the regressive changes seen in the glia nuclei. Their forms were extremely varied. Some were seen as almost circular, small darkly staining bodies in which no distinct granules could be seen, and in many of these no cell body could be made out ; in some the cell body was suggested by a halo surrounding the nucleus. Other nuclei stained very faintly and contained small chromatin clumps, about these also no distinct cytoplasm could be differentiated. The size of the regressive 
nuclei was of course very variable, some were about normal in size and were filled right up with small chromatin granules. Besides the atypical form seen, there were of course many glia nuclei undergoing progressive changes, these were larger than usual and showed all the signs which have been mentioned before of glia proliferation.

The sections which have just been studied were all stained with thionin and the Van Gieson picture did not add anything new. In explanation of the fact that the changes noted had largely taken place in the cortex, it should be mentioned that the lesion was quite a mild one, although owing to an accident to the capillary pipette while the instruments were being prepared for operation the amount of irritant could not be as accurately determined as in the other cases.

We have seen then that the changes which were noted at the end of three days were really: An increase in the proliferative activity seen at the end of 48 hours with more marked regressive changes in the glia nuclei, and finally the last phase in the life history of many of the hæmatogenous elements which made up the exudate. Certain other elements were seen at this time, which will be briefly touched upon. They were long narrow cells, irregular in outline, closely resembling adventitial nuclei, and it is probable that they are elements closely related to them. At times they were only of moderate length and were more or less cresentic.

The absence of any plasma cells has been spoken of elsewhere, and it is only fair to state that possibly in other sections which were not studied closely these elements might have been found. It has been the habit of the writer to take one section and make nearly all observations from a study of this; because once oriented regarding the points to be learned by a study of the particular slide, the task was much easier and the study more thorough and searching, because various forms could by comparison often be traced through different phases.

At the beginning of the study of the tissue which was secured four days after the irritant was applied; it is well to state that owing to an accident while the operation was in progress the amount of the irritant applied was slightly greater than in any previous case in consequence of which the lesion produced may 
appear very acute when one considers the length of time that had elapsed, viz., 96 hours. The rabbit used was a normal adult.

The exudate which we have seen by a study of the third day section had largely disappeared, was still less noticeable, only an occasional irregular chromatin clump was found, indicating the regressive process going on in a leucocyte. A few plasma cells were seen, although they were not present or at least were not observed at the end of three days. They were present in the cortex and in the area which had been injured by the direct contact of the acid.

The most striking features in the picture at this time, however, were: the continued activity in the fibroblasts, and secondly, the active proliferation of the reticulated cells. The activity in the fibroblasts was possibly even more conspicuous than at the end of 36 hours ; mitosis was seen to be going on in many places and a further process was noticed-that the newly formed fibroblasts were actively engaged in forming new blood-vessels-and in some of these vessels red-blood cells were seen. Before this time the new vessels were all formed from preexisting vessels branching off as capillaries, etc., so that the process which presented itself at this stage was decidedly an advance. Fibroblast trains were also seen and were more numerous than at the end of the third day.

The fibroblast activity of course caused a great increase in the number of connective-tissue elements and resulted in a very considerable increase in the width of the pia.

The second feature in the connective-tissue proliferative activity was the great increase in the number of the reticulated cells. They were everywhere present, but most in evidence in the damaged cortex. They presented very many different forms, some small, some very large, some regular, others quite irregular in outline, some spherical in shape.

Many features in connection with the life history of these most interesting cells were observed. The rapidity with which they appear, attain adult form, divide and undergo regressive changes was indeed striking. Some cells were seen where the tag of protoplasm indicating a very recent cell division could still be seen, and in these cells mitosis had begun. A somewhat earlier stage was also noted, where the two cells had not separated, 
where two distinct nuclei were present, but the cytoplasm had not yet divided.

The third phase exemplified by the regressive forms was also quite conspicuous; they varied from cells where there was only a slight diminution in the number of vacuoles-to cells where only little tags remained attached to the nuclei-the vacuoles having entirely disappeared. Following this further, various reticulated cell nuclei were seen where no cytoplasm could be made out at all, and in some instances these nuclei were seen in the vacuoles of other more recently formed reticulated cells. Here they had actually been prey for their younger brother phagocytes. A considerable number of reticulated cells were observed to have two nuclei and an occasional one with three. These of course were cell nuclei and not degenerated cell nuclei that had been taken up because these later could be differentiated by being always in vacuoles.

That these cells, the Gitterzellen or reticulated cells are the most important phagocytic elements in the cortex, was over and over demonstrated. It has already been noted that they contain regressive reticulated cell nuclei; they were also seen to have taken up glia nuclei and regressive forms of ganglion cell nuclei. No other cells were observed to have a phagocytic function in any section studied.

Certain regressive changes in the reticulated cells, which have already been mentioned, made it hard (in some instances) to be sure whether we had to deal with regressive glia forms or reticulated cells. But on a closer study it was found to be almost invariably true that the glia nucleus was surrounded by a small amount of cytoplasm, and often the thread-like processes could be traced for a short distance, but in the case of the reticulated cell nucleus where the tags of protoplasm suggested the possibility of its being a glia nucleus, the cytoplasm was absent and the spider-like processes were not seen. The connection between the various glia cells of course also aided in the differentiation. Several instances of mitosis in glia nuclei were seen and here the rosary-like appearance of the chromatin granules just inside the nuclear membrane was observed. Hypertrophic glia cells were seen, very large forms containing an increased amount of chromatin. Owing to the severity of the lesion various regressive 
forms were seen in both glia and ganglion cells. To summarize briefly, the changes at the end of 96 hours were seen to be largely proliferative as regards the connective-tissue elements. Keeping in mind, of course, the fact that the reticulated cells, owing to the brief span of their activity, also showed many regressive changes. The changes in the glia were proliferative and regressive and in the ganglion cells the changes were all regressive.

This brings us to a consideration of the changes occurring at the end of five days. The rabbit used in the experiment was only half-grown. It stood the operation rather badly; but after being liberated when the operation had been completed, it hopped about and showed nothing abnormal up to the time when it was etherized. These factors, particularly the difference in age, must be kept in mind because the results obtained were quite different to those obtained at earlier stages, and it seems probable that such a factor may have had some importance in determining the variation.

In looking over sections where only a small amount of irritant had been applied, it was at once evident that the changes were largely confined to the pia, the changes in the underlying molecular zone being so slight that they really did not enter into reckoning at all. The other changes with which we had to deal were found to be more easily studied in sections where the more severe lesion had been induced; so that the observations were chiefly confined to these.

The most striking feature of the five-day picture and the one which was constant in all sections was the great increase in the number of plasma cells. They were found in large numbers in every field studied. That they were present at the end of four days has already been noted, but their number at that time was quite insignificant when compared with their frequency in the five-day sections. That they are present in various inflammatory exudates, of course is well known, but the variability in their appearance both as to the time of their occurrence, and as to their frequency strongly impressed itself upon my mind, and, it is really the point of importance elicited by the study of the sections at this time. As to their form they varied from the most characteristic types to those where quite marked regressive changes were under way. In the case of the typical plasma cells, 
the rather large cell body, fairly regular in outline, with slightly staining cytoplasm, the eccentric more darkly staining nucleus containing a number of chromatin masses arranged about the periphery, as a rule all staining darkly, with the exception of one small clump, more centrally located, whose staining reaction was the same as that of the cell protoplasm-that is light. The darkly staining basophilic clumps did not at all suggest the rosary-like arrangement spoken of elsewhere as the characteristic of premitotic states in the reticulated and glia cell nuclei.

The less characteristic plasma cells show differences in the staining reaction. Occasionally the nucleus would stain very darkly throughout, and its structure could not well be made out. This condition suggested the probable early onset of still more marked regressive changes, and this was found to be true in certain instances. Occasional bi-nuclear forms were also present as one would expect, with the very considerable increase in the number of plasma cells, there was also an increase in the number of other hæmatogenous elements, and a marked hæmatogenous exudate was seen in certain fields, but its character varied somewhat from that seen at the end of 24 and 48 hours. And the most characteristic difference was in the absence of the regressive forms of leucocytes, chiefly the polynuclears; an occasional polynuclear was seen both in the pia, and of course in the blood-vessels, but they were not undergoing degenerative changes. A fairly large number of mononuclear was seen, some very large forms almost like myelocytes; of course a few leucocytes were seen to be breaking down, but their number was quite inconsiderable.

The connective-tissue proliferation continued, many fibroblasts were seen undergoing mitosis, and some beautiful karyokinetic figures were observed. Some of the best of these were in the endothelial cells. Here all the various phases could be seen from the early pre-mitotic condition of the nucleus to the establishment of the two nuclei and the beginning division of the cytoplasm. In some of the endothelial cells the spherical shape of the nucleus was well seen and this was characteristic of those elements when found in a connective-tissue hyperplasia.

In the sections studied, even where the lesion was most severe, very little change could be made out in the cortex. The very 
evident regressive conditions present in sections of previous days were absent here. Unfortunately also, nearly all the sections showed a very light staining of the molecular zone so that the exact condition there could only be ascertained with difficulty. But one feature which was rather puzzling was the absence of the reticulated cells, or rather one should say they were not observed, because it is quite possible that owing to the very mild staining reaction of the upper zone of the cortex they may have been present, but not detected owing to the mild nature of the irritation, the cortex being (as has been noted) almost intact; it is extremely probable that they would at least be greatly reduced in numbers. It is also true that they were not seen anywhere in the pia-arachnoid in the sections studied. This observation would merely add to what already has been said regarding their function, because in these sections the changes were almost entirely limited to the pia-arachnoid, and on that account one would not expect to find many phagocytic elements present. As in the case of the sections studied before, almost all the observations made were on sections stained with thionin. From a brief study of the Van Gieson sections the chief thing noted was an increase in the amount of the collagenous material present.

The study of the sections made at the expiration of six days was rather unsatisfactory for the reason that the rabbit used for the experiment stood the operation quite badly, struggled considerably, and bled quite profusely from the nose during the progress of the operation. After being liberated it hopped about and seemed to be in a fairly good condition. On the morning following, however, it was quite dull and stupid, could hardly be urged to change its position and was not eating well. This condition lasted for two or three days when the animal became somewhat more lively, and by the sixth day to all outward appearances was not very abnormal.

The sections at once showed, however, that one had other conditions to deal with than the lesion produced by the application of the irritant. A very severe cerebral hæmorrhage had taken place, involving all the layers of the cortex and extending even below it into the white matter. Red-blood cells were seen in large numbers lying free in the cortex, and the cortex itself in some places had quite lost its structure. Everywhere there were 
great numbers of reticulated cells, in some of the fields they were so dense that they were overlying one another. This reaction in the injured cortex was very characteristic and served to illustrate one of the processes which follows a cortical hæmorrhage under any condition; the appearance of a vast number of the reticulated cells, whose object is to remove the tissue that has been devastated and is undergoing regressive changes.

The pia showed an overwhelming number of fibroblasts; they were present in such great numbers that it was extremely diffcult to study their structure or arrangement or rather lack of arrangement. They were really piled up in banks. In places where they were not so numerous and where their characteristics were not obscured by their quantity; it could be seen that mitosis was still going on. Plasma cells were seen occasionally in such areas.

Owing to the conditions which have just been mentioned, it was found quite impossible to make any accurate or careful observations, for this reason we passed directly to a consideration of the state of the pia-arachnoid seven days after the irritant had been applied. The rabbit used in this instance was a full-grown healthy animal. It stood the operation well, but it was noted at the time that it bled quite profusely throughout the operation. No other untoward incident is recorded, however, in the time that elapsed before it was etherized.

Unlike the sections at other times and clearly indicating an advance in the process, the sections at the end of seven days showed an arrangement of the newly formed connective-tissue elements, characteristic of fairly late progressive changes. The fibroblasts had become oriented in parallel rows, the formation being very dense, of course causing a very considerable increase in the thickness of the pia. The mitoses were seen much less frequently, and this was doubtless owing to the large number of fibroblasts already present, and also probably to the slight amount of injury sustained by the cortex in the lesion at this time.

The arrangement of the cells in rows is a more mature phase in the changes following an inflammatory process than the conditions observed at any time previous, and would suggest that the progressive reaction resulting in the overgrowth of connectivetissue elements has almost attained its acme. Of course the individual reaction of each rabbit and the probable slight variation 
in the amount of irritant applied have to be considered. For this and other reasons one cannot be too dogmatic, as we have seen by the study of the changes at various other periods, and one of the striking characteristics in the elements present has been the variability in number of the element at different times.

Plasma cells were found in much less abundance than at the end of the five days, and relatively less abundant than at the end of the sixth day. The reticulated cells were few in number, and this probably also followed because of the slight injury which had been done to the cortex. Certain very interesting forms were observed in studying the fibroblasts which had not been encountered before. They were regressive in character and assumed many bizarre shapes. Some were stellate, others arrow-shaped, and many long narrow cells almost identical in some cases with adult adventitial nuclei. Some of these cells showed by their staining reaction that not only were their physical properties altered as was shown by their forms, but also that they had undergone a chemical change. Cells which under normal conditions showed a mauve reaction to thionin, were green. These cells were occasionally seen cut off from the other fibroblasts and apparently were not functionally active at times. They would be seen to be hemmed off by the dense formation of fibroblasts already mentioned, and occupying an otherwise comparatively clear area. I shall not advance any explanation as to why these forms should have been in the picture at this time.

The dura mater was seen in some of the sections studied at this time, and since no mention has been made of it before we may digress just long enough to mention its connection with these experiments.

When the opening was made in the vertex in the cases operated upon, the irritant was applied directly to the dura and reacted upon the pia-arachnoid through the dura. However, when the animal came to autopsy and the skull was removed piece by piece, the dura was also taken off, and since this work dealt only with the pia-arachnoid, no attempt was made to preserve the dura. Because of this, no section studied until the one present showed any trace of the dura. However, at this time it was seen. In its structure it is a connective-tissue membrane, made up of many strands running together. It is less vascular than the pia and of 
course does not show the loose spongy arrangement seen in the pia-arachnoid.

The change at the end of the next 24 nours, that is, in the rabbit killed eight days after operation, can well be described under three headings: those in the epiblastic tissue, those in the mesoblastic, and the difference in the hæmatogenous elements seen. The rabbit was a normal adult and nothing was noted that would modify the observations made. The connective-tissue hyperplasia was seen especially well in the sections where only a mild lesion had been caused. Here the fibroblast overgrowth was seen to be continuing, many new small vessels of the pia-arachnoid were seen. The mitoses in the fibroblasts were not quite so numerous as seen in the sections at the end of the seventh day where the lesion was relatively of the same intensity. The differentiation of the newly formed fibroblasts was more noticeable than at any other period. Some had assumed the position of adventitial cells, while others formed the lining of the new vascular channels. Some of the regressive fibroblast forms noted in the study of the sections of the previous day, were seen in the large vessels. The glia proliferation in these sections was quite striking; many nuclei were seen in the pre-mitotic stages, glia clusters were also quite numerous. The ganglion cells did not show many changes and this of course was due to the nature of the lesion. As a consequence of the mildness of the lesion and the few regressive changes seen, the reticulated cells were less numerous, but in some of those observed mitosis was seen well under way.

The blood elements were quite numerous, the plasma cells being present in greatest abundance. They were rather more frequently seen than at the end of the seventh day. The nuclei of some of the plasma cells were seen to be in an active condition suggesting an oncoming mitosis, and later some cells were seen in the process of division; in one cell observed the two newly formed nuclei were very characteristic. An occasional chromatin clump was seen, some having the form of the nuclei in the polynuclear leucocytes. A number of lymphocytes was also seen. In the case of the severe lesion a considerable area of the cortex had undergone a degenerative process and a low power picture of the tissue was extremely characteristic. One could make out the connective tissue bounding the area where regressive changes 
were in progress, marking it off clearly from the surrounding cortex. With the higher power the great number and the marked activity of the reticulated cells was seen. They were everywhere present and many contained foreign matter-granules of various sizes-and the regressive forms of the ganglion cells. The action of the reticulated cells in removing the granular débris, all that remained of the cortex, was plainly evident.

Just below the injured zone proliferating glia nuclei were seen in very considerable numbers. The fibroblast invasion of the injured zone was also well under way, and here and there definite fibroblast trains were seen.

The rabbit used in the next experiment was a healthy adult animal. Nothing of special note occurred during the time that elapsed between the operation and the death of the rabbit. Two lesions were caused as in previous operations. The study of the sections of the severe lesion revealed very little that has not been noted in the corresponding lesion at the end of the eighth day. In the less severe lesion, however, it was seen that the ninth day picture in certain fields showed a slight advance in the process. The mitosis was less conspicuous both in fibroblasts and reticulated cells, but the proliferative activity of the reticulated cells is, as we have seen elsewhere, almost entirely dependent upon the degree of severity of the lesion in the cortex. That is, the reproduction of the cells is determined by the necessity of their presence for the performance of their phagocytic function.

The fibroblast picture in certain areas was extremely interesting. In such fields they made up a network of very delicate structure, and in the interstices of this network reticulated cells were everywhere seen. Plasma cells were seen to be present in quite large numbers, they were probably more numerous in sections of the severe lesion. In general outline the pia-arachnoid appeared even thicker than at the end of eight days, and this thickening was mainly due, to the greatly increased number of fibroblasts, which undoubtedly was the result of extreme proliferative activity at an earlier stage in the development of the picture.

The sections made at the end of Io days were from a normal healthy adult rabbit, in this animal only one lesion was causeda mild one. Here, again, although the changes indicated a slightly later stage, nothing very markedly suggestive was noted. 
Regarding the reticulated cells which were still present, the only unusual feature observed was the degeneration of quite a considerable number. Except for this feature nothing else was seen that has not already been spoken of. The fibroblasts still showed some activity and the increase in their number was much less marked than in sections of earlier days and this suggested the possibility that the height of the process had been almost reached. In some of the fibroblast nuclei, that is, in those cells which still were seen to be in an active state, the chromatin had assumed a girder arrangement, one band passing across the center of the nucleus. The hæmatogenous exudate was observed to be present, plasma cells being seen here and there, also a smaller number of mononuclear leucocytes, and in one the presence of two nuclei was observed.

Owing to the short time available it was found impossible to continue these experiments at present, and this was much regretted because the process was really in an acute stage; however, the observation of further stages up to the conclusion of the process will be continued at a later period. The work is presented merely as a preliminary report of the acute phase of a process which later would doubtless show many interesting regressive changes. It is the aim of the writer at some future date to present the findings in the later stages of the process.

To sum up, I would present the following conclusions:

I. That in an acute, aseptic inflammatory process which has proceeded as far as the Ioth day, the most striking feature is the variability in the time of the appearance, and in the number of the various elements present at different times.

II. Further, that the study of a single individual element is not sufficient to indicate how far the process had gone. To this end a general survey of all the elements is necessary.

III. That the variability in the character of the elements in different phases of the process is very slight. Elements observed in a certain condition at the end of the third day may be seen in identically the same form at the end of eight days.

IV. That plasma cells are at all times conspicuous, in the early stages being present in very large numbers; then somewhat less numerous, and again, later in the process being relatively in- 
creased in numbers. But throughout the whole process their presence is a characteristic feature.

V. And lastly, the fact that at no stage of the process were any Mastzellen observed. This was quite noteworthy, when certain features in the process, namely, the presence of various other hæmatogenous elements, is kept in mind.

The photomicrographs accompanying are intended to represent various phases of the process, as explained by the legends printed with the same.

\section{DESCRIPTION OF PLATES.}

Fig. 1.-Shows section of normal cortex cerebri of rabbit with piaarachnoid. The membrana limitans interna and externa are shown and an occasional vessel cut in section may also be seen. It will be observed that there is a very slight amount of connective tissue running from the pia-arachnoid into the cortex in the normal condition, and there are no vascular elements free in the tissue.

Fig. 2.-Illustration of sections made at the end of 24 hours. The very strong reaction to the glacial acetic acid is here shown. The great number of vascular elements free in the tissue and the greatly increased number of blood cells in the vessels shown in section is also evident. The thickness of the pia-arachnoid is greatly increased and this increase is due not to connective-tissue proliferation but to vascular engorgement.

Fig. 3.-(Taken at the end of 72 hours.) This photograph shows a further stage in the inflammatory (reactive) process. Connective-tissue proliferation is here well seen-the pia-arachnoid is greatly thickened and is seen to be due to a great increase in number of fibroblastic elements. It will also be seen that the connective tissue actively extends down into the cortex, particularly in the molecular zone. Vascular elements are seen to be still free in the tissue but they are much less numerous than in the preceding photograph.

FIG. 4-This illustration shows the process at the end of five days. The connective-tissue proliferation is very much more marked, and the pia-arachnoid is greatly increased in thickness in consequence. The activity of the mesoblastic tissue in the deeper layers of the cortex is also seen. Vascular elements are here very little in evidence. 
AMERICAN JOURNAL OF INSANITY, VOI. LXIV, No. $1 . \quad$ PLATE I.

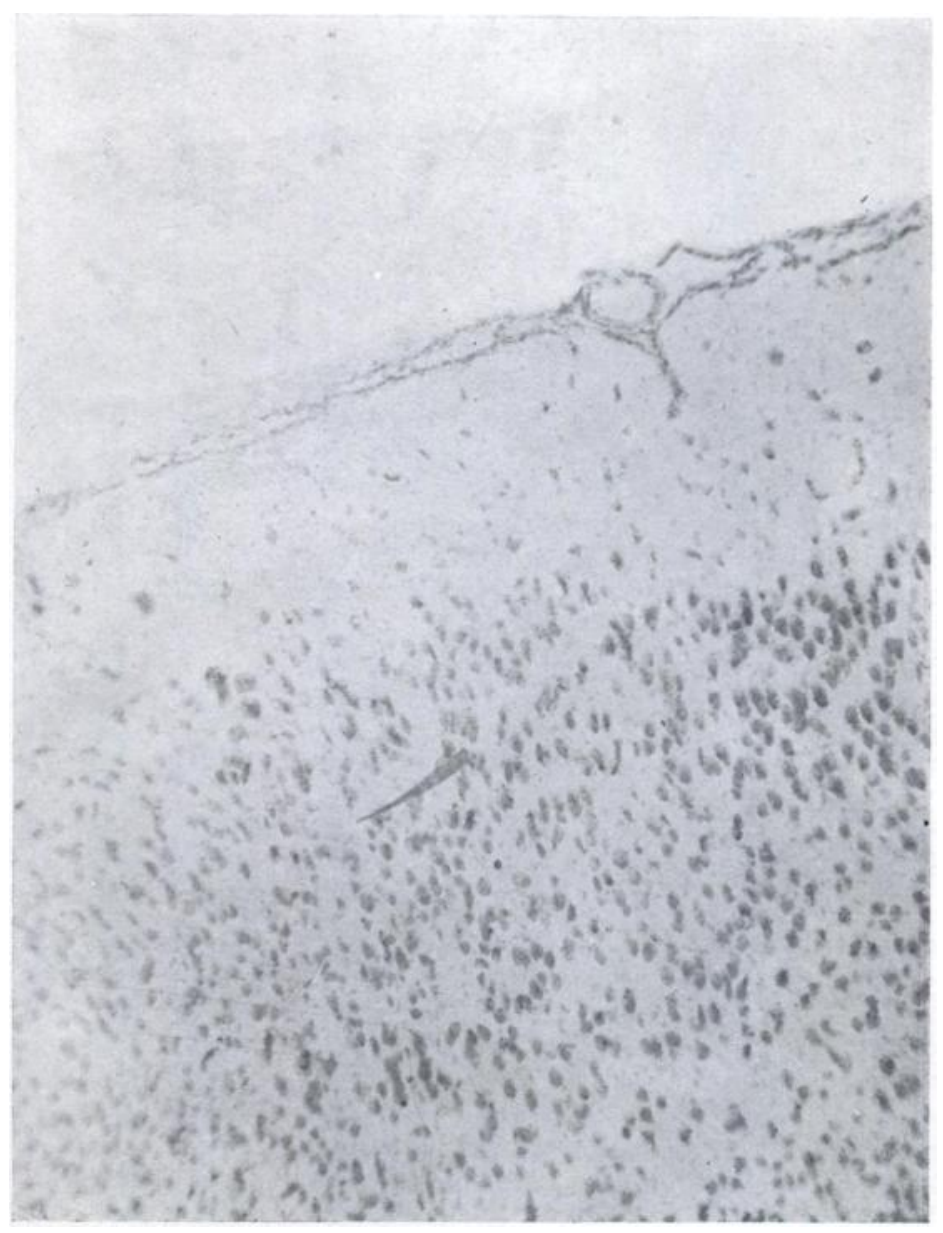

FIG. I. 
AMERICAN JOURNAL OF INSANITY, VoI. LXIV, No. $1 . \quad$ PLATE 11.

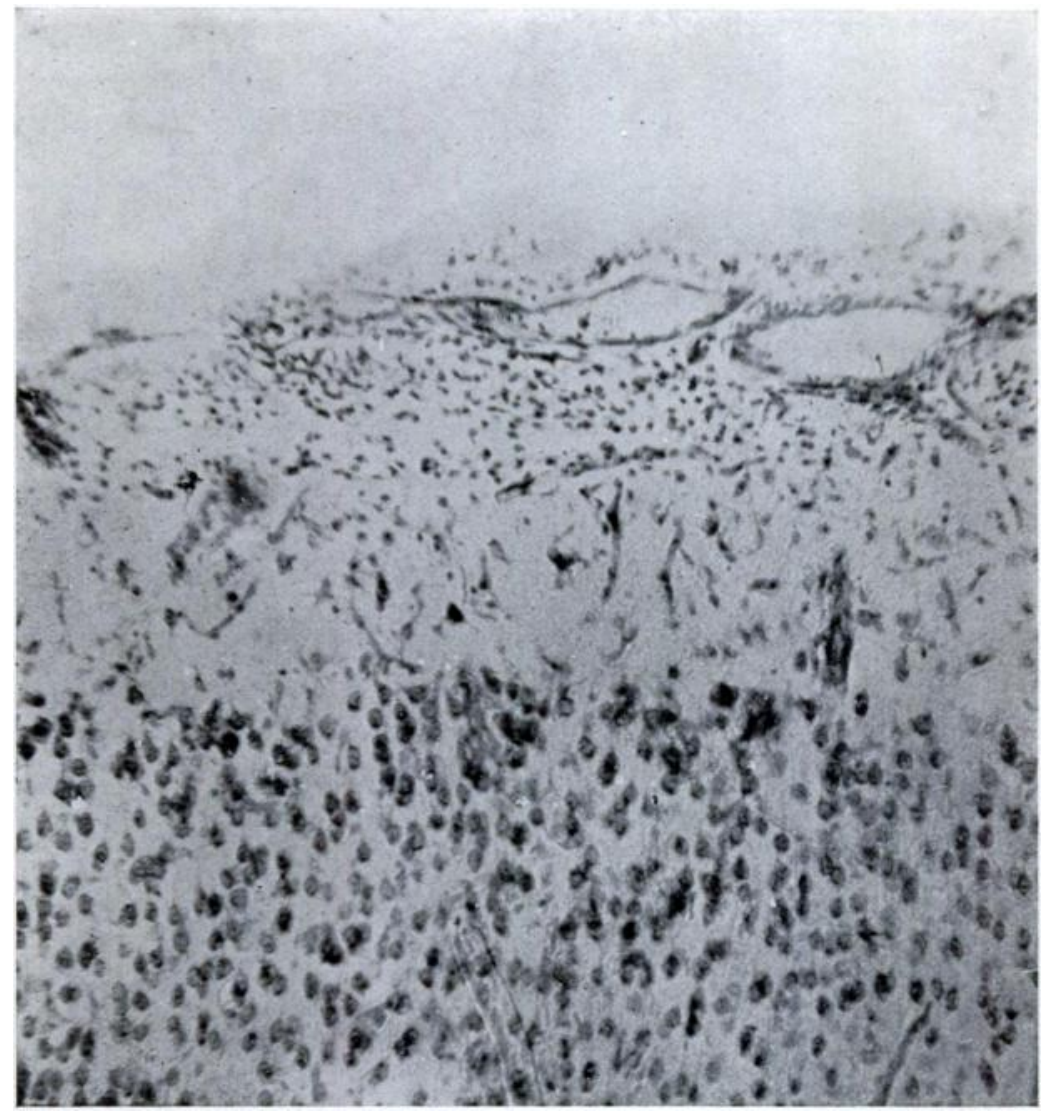

Fig. 2. 
AMERICAN JOURNAL OF INSANITY, VoI. LXIV, No. 1. PLATE III.

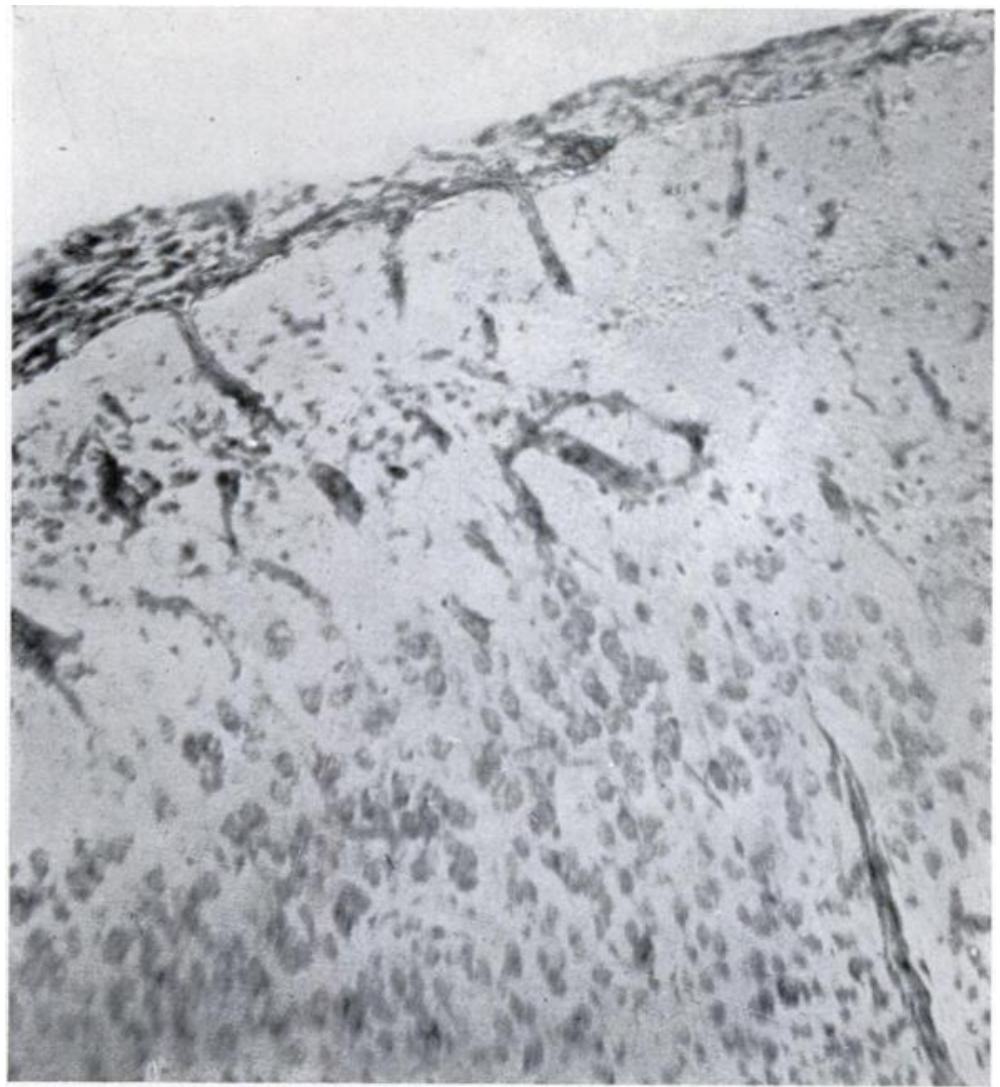

Fili. 3.

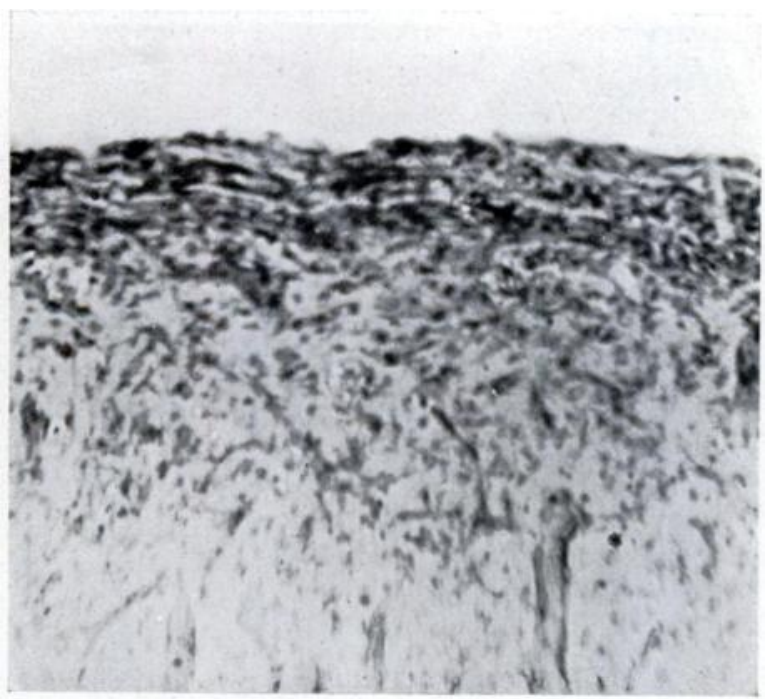

Fig. 4 . 